\title{
Erratum
}

\section{Subclinical inflammation affects iron and vitamin A but not zinc status assessment in Senegalese children and Cambodian children and women - ERRATUM}

Marion Fiorentino, Marlène Perignon, Khov Kuong, Chhoun Chamnan, Jacques Berger and Frank T Wieringa

First published online 20 February 2018

doi: 10.1017/S1368980017003809. Published online by Cambridge University Press, 18 January 2018

The above article was published with incorrect author affiliation information.

The correct affiliation is: Institut de Recherche pour le Développement (IRD), UMR 204 Nutripass, IRD-UM2UM1, Montpellier, France.

This error has now been rectified in the online article.

\section{Reference}

Fiorentino M, Perignon M, Kuong K, Chamnan C, Berger J \& Wieringa F (2018) Subclinical inflammation affects iron and vitamin A but not zinc status assessment in Senegalese children and Cambodian children and women. Public Health Nutrition, 1-12. doi: 10.1017/S1368980017003809 